\title{
The South Aegean seismological network - HSNC
}

\author{
G. Hloupis ${ }^{1}$, I. Papadopoulos ${ }^{2}$, J. P. Makris ${ }^{3}$, and F. Vallianatos ${ }^{2}$ \\ ${ }^{1}$ Department of Electronics, Technological Institute of Athens, 12210 Egaleo, Athens, Greece \\ ${ }^{2}$ Department of Natural Resources and Environment, Technological Institute of Crete, P.O. Box 89, 73103 Chania, Greece \\ ${ }^{3}$ Department of Electronics, Technological Institute of Crete, P.O. Box 89, 73103 Chania, Greece
}

Correspondence to: F. Vallianatos (fvallian@ chania.teicrete.gr)

Received: 27 October 2012 - Revised: N.A. - Accepted: 20 March 2013 - Published: 30 April 2013

\begin{abstract}
In the present work, the installation and the technology applied for the operation of the Hellenic Seismological Network of Crete (HSNC), located in the front of the Hellenic Arc, are presented. The topology, the communication modes (wire and satellite) along with data collection and processing methodologies applied leads to the operation of a new seismological infrastructure in South Aegean, one of the most seismically active regions in Europe.
\end{abstract}

\section{Introduction}

Greece is located on a tectonically active plate boundary at the convergence of the Eurasian and African lithospheric plates. Crete and the southern Aegean are moving together as a coherent block. The divergent motion between the Aegean block and mainland Europe is indicated by an extension zone in the northern Aegean, with Crete and Aegean diverging from mainland Europe at a rate of about $3 \mathrm{~cm} \mathrm{yr}^{-1}$ (McClusky et al., 2000) while Africa is moving northward relative to Europe at a rate of about $1 \mathrm{~cm} \mathrm{yr}^{-1}$ (Dewey et al., 1989), see Fig. 1. The compressional motion between Europe and Africa causes the subduction of the eastern Mediterranean lithosphere plate to form the Hellenic Arc and Trench (Comninakis and Papazachos, 1972; Makropoulos and Burton, 1984). The tectonic processes that are taking place in the subducting slab in the Aegean area control the distribution of both seismicity and volcanism (Karagianni et al., 2005). More than 60 per cent of the European seismicity is observed in this region with earthquake magnitude up to $M_{\mathrm{W}}=8.2$ (Papazachos, 1990). The South Aegean region is characterized by shallow and intermediate depth seismicity with magnitudes that exceed Ms > 7.0. In the past few years, many temporary seismological networks have been installed for a varying period of time in the area (Harjes et al., 1997; Delibasis et al., 1999; Becker, 2000; Jost et al., 2002; Meier et al., 2004). Permanent network installations in the area have been deployed by GeoForschungsZentrum, National Observatory of Athens and MENET project. The seismological data are collected by the Hellenic Unified Seismological Network (HUSN) but as pointed out by Alessandro et al. (2011) some seismogenic areas of Southern Greece (e.g. Cyclades) probably are not adequately covered by the HUSN emphasizing to the need for the operation of a dense permanent network of seismological stations in and around Crete island. The main advantage of having a dense network of stations in this area is to decrease the interstation distance, which will result in better locations and a lower magnitude of completeness, supporting studies of hazard assessment and contributing in the understanding of the seismotectonic complexity of the area. Furthermore, due to high seismic activity in the area, a dense network would be able to provide data to reporting centers but at the same time to correspond to an increasing demand of information from civil protection authorities. This paper aims to inform the scientific community about the installation, operation and the promising capabilities of the Hellenic Seismological Network of Crete (HSNC), a modern network located in the front of the Hellenic Arc.

\section{Network description}

Nowadays, the Hellenic Seismological Network of Crete (HSNC) consists of 12 stations. The location of each station is depicted in Fig. 2 (and the recorded events for a period of 2008-2011), and station details are presented in Table 1. Most of the stations (except RODP, KOSK, THT2) are registered to International Seismological Centre (ISC) and the network is listed by International Federation of Digital 


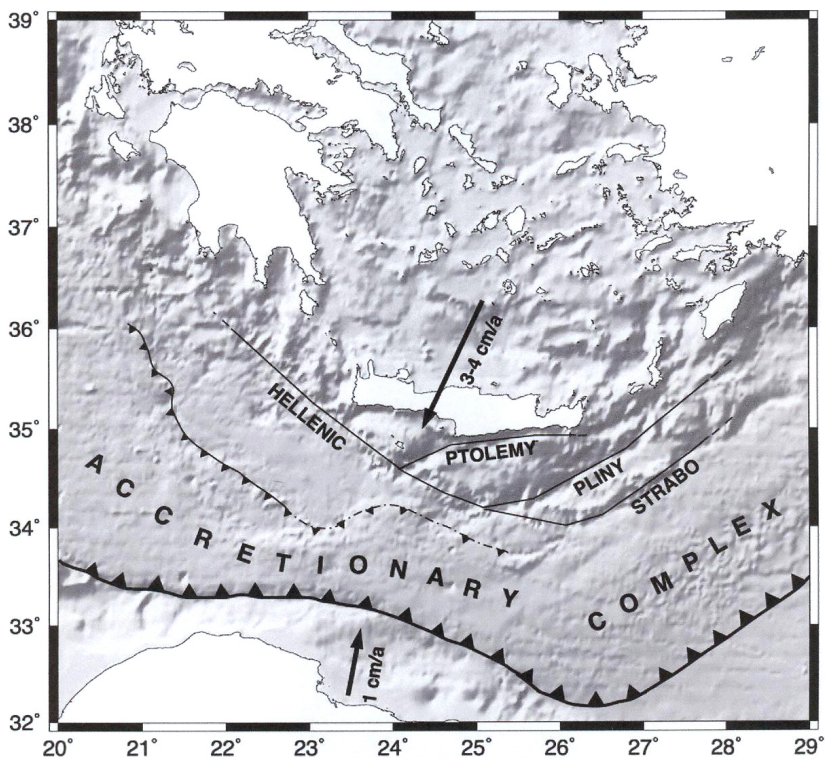

Fig. 1. Geodynamic setting of the Hellenic arc and approximate relative motion vectors (after Jackson, 1994; Lallemant et al., 1994; Le Pichon et al., 1995) for Crete and Africa with respect to stable Europe.

Seismograph Networks (FDSN) with the assigned permanent network code HC.

All stations are equipped with a 3rd generation data logger (Reftek's Data Acquisition System -DAS 130-01; www. reftek.com). This selection is justified by its advanced performance specifications with emphasis to its decreased operational power capabilities, dual 3-channel inputs, variable sample rates, and multiple ways of telemetry communications. At an earlier state, they were equipped with Guralp CMG-40T 1sec sensors, which are being gradually replaced with Guralp CMG-3ESPC 60 and 120 s broadband sensors.

Continuous, real time communication between the stations and the Network Centre for Data Storage and Analysis Centre (NCDSA) is achieved by means of two types of links, wired and satellite. The wired links from remote seismological stations to NCDSA rely on a Virtual Private Network (VPN). The VPN is based on Multi Protocol Label Switching (MPLS) technology over conventional Asynchronous Digital Subscriber Lines (ADSL). MPLS provides security levels similar to Frame-Relay technologies with lower cost. The VPN built for the purposes of HSNC is outlined in Fig. 3. For backup purposes, the routers that are used have the option to connect to the VPN through ISDN lines. This is selected in order to ensure that in case of ADSL failure the data connection is kept alive.

When the nearest network point is inaccessible due to the distance and the desirable bandwidth, the solution of a wireless link becomes imperative. Furthermore, due to the demand to install stations in small isolated isles in South Aegean, an alternative to wired telemetry mode is required.
Table 1. List of seismic station of the HSNC along with their coordinates, codes and sensor type.

\begin{tabular}{llrrr}
\hline Station & Type & Latitude $(\mathrm{deg})$ & Longtitude $(\mathrm{deg})$ & $\begin{array}{r}\text { Eleva- } \\
\text { tion }(\mathrm{m})\end{array}$ \\
\hline KNDR & Broadband & $35.234^{\circ} \mathrm{N}$ & $23.686^{\circ} \mathrm{E}$ & 25 \\
FRMA & Short Period & $35.014^{\circ} \mathrm{N}$ & $25.733^{\circ} \mathrm{E}$ & 33 \\
CHAN & Broadband & $35.519^{\circ} \mathrm{N}$ & $24.042^{\circ} \mathrm{E}$ & 34 \\
KSTL & Short Period & $35.304^{\circ} \mathrm{N}$ & $25.071^{\circ} \mathrm{E}$ & 70 \\
PRNS & Short Period & $35.365^{\circ} \mathrm{N}$ & $24.501^{\circ} \mathrm{E}$ & 51 \\
KTHR & Broadband & $36.261^{\circ} \mathrm{N}$ & $23.004^{\circ} \mathrm{E}$ & 315 \\
TMBK & Broadband & $35.072^{\circ} \mathrm{N}$ & $24.766^{\circ} \mathrm{E}$ & 17 \\
STIA & Short Period & $35.202^{\circ} \mathrm{N}$ & $26.091^{\circ} \mathrm{E}$ & 89 \\
KOSK & Broadband & $36.7516^{\circ} \mathrm{N}$ & $26.9785^{\circ} \mathrm{E}$ & 269 \\
RODP & Broadband & $35.5604^{\circ} \mathrm{N}$ & $23.7577^{\circ} \mathrm{E}$ & 40 \\
THT2 & Broadband & $36.4351^{\circ} \mathrm{N}$ & $25.4218^{\circ} \mathrm{E}$ & 338 \\
GVDS & Short Period & $34.8435^{\circ} \mathrm{N}$ & $24.0902^{\circ} \mathrm{E}$ & 164 \\
\hline
\end{tabular}

From experience, in most of the cases where the line distance of a remote station from NCDSA is over $200 \mathrm{~km}$, the satellite link (VSAT) is proven to be the only reliable long-term and cost effective solution. The common (and low cost) solution in VSAT IP-based multipoint links provides a partial mesh or star topology, where each remote site can communicate with the others via provider's central hub (double hop). Unfortunately, this solution has the drawbacks of greater network delay and the dependence on provider's Quality of Service (QoS). To overcome these limitations, we installed and deployed for the HSNC its own private satellite hub allowing single-hop communication between central hub and VSATs. The selection was the iNFINITI platform by iDirect (Dallas, USA), which met HSNC's data transfer requirements in a high level of accordance (upload $128 \mathrm{kbps}$, download 256 kbps, D-TDMA, Turbo FEC 0.793 download - 0.66 upload, availability $99.8 \%$ ). The satellite carrier is Hellas-Sat2 which is based on EuroStar E2000+ (launched in 2003) at $39^{\circ} \mathrm{E}$ and expected to have $18 \mathrm{yr}$ of operation. Schematic representation of the VSAT satellite topology of HSNC is depicted in Fig. 4.

\section{Data collection and monitoring}

At the Network Centre for Data Storage and Analysis Centre (NCDSA) of HSNC has been adopted a LAN topology that leads to a realization with three data service points. The first service point (Primary server) receives and stores all the data from remote stations and collaborating networks, as the Seismological Network of the Aristotle University Thessaloniki (HT, THE). The second service point (Secondary server), acts as a backup to the first one and the third one (Diskloop Data Server) is the point where the seismological signal processing is taking place, as schematically is depicted in Fig. 5.

The data collection software is a commercial product ( $r t p d$ from Reftek Inc.) which implements RTP protocol. It runs on Linux OS and is responsible for collecting and archiving 


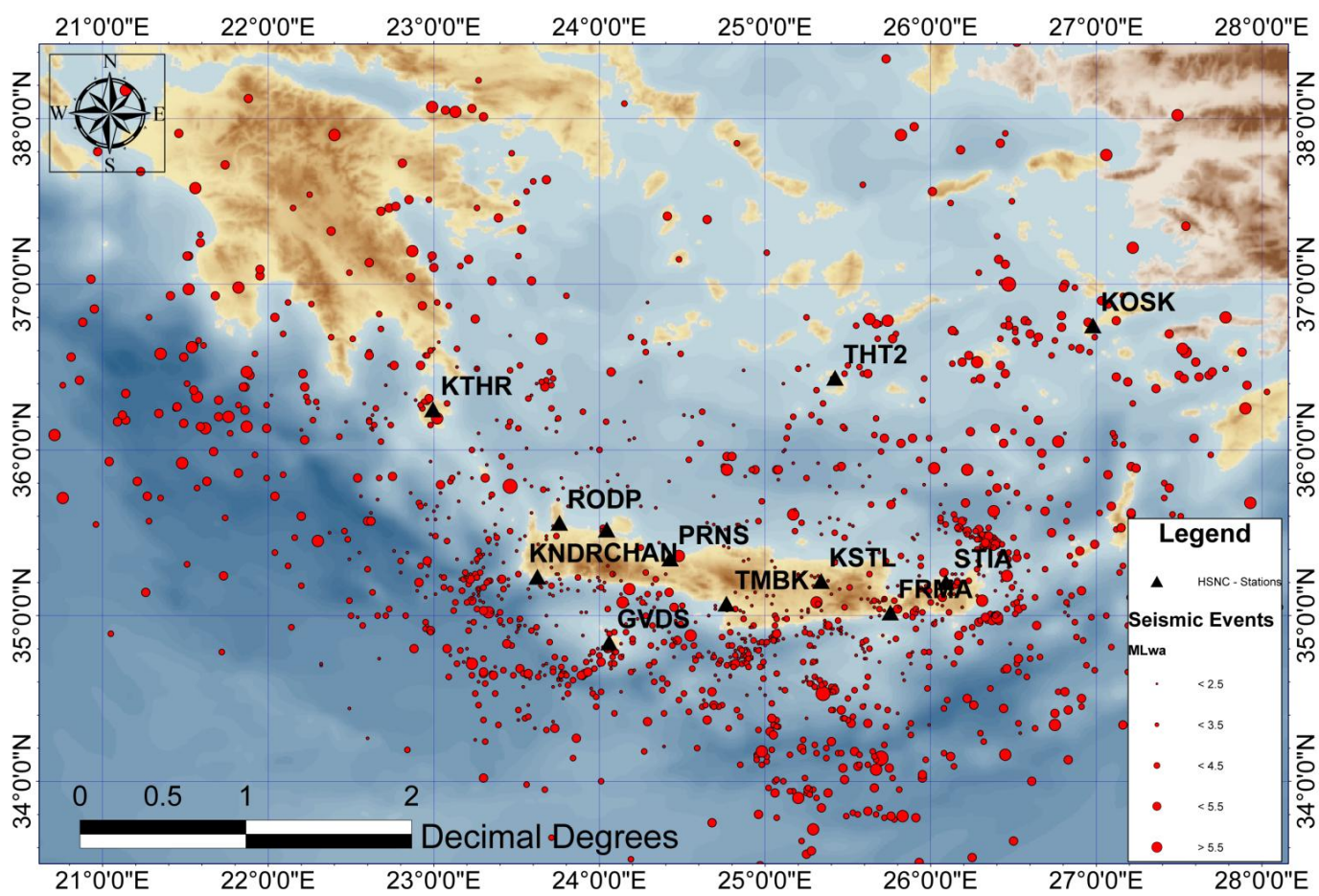

Fig. 2. HSNC stations and the seismic events recorded from 2008 until 2012.

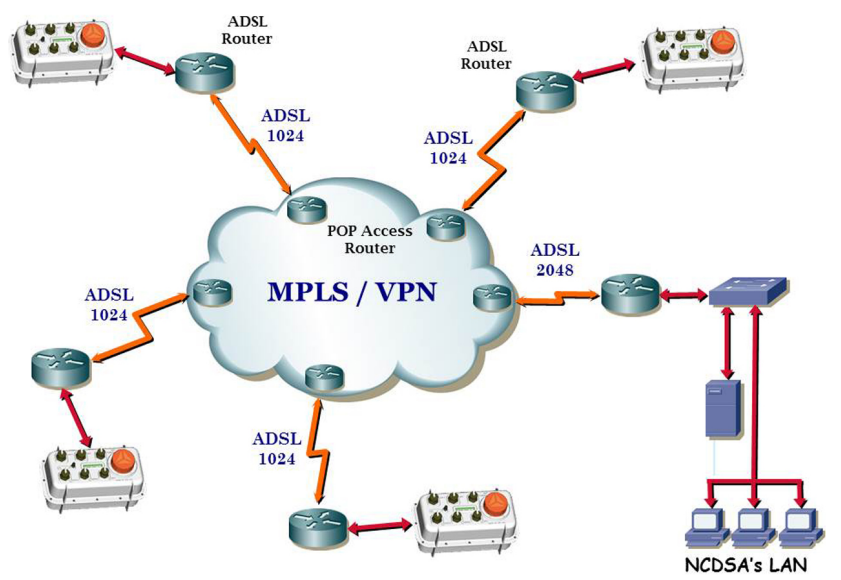

Fig. 3. MPLS/VPN topology used by HSNC.

data from the remote stations to the NCDSA. It also performs quality control and acknowledgement packets back to the stations. Acting as a server, rtpd can respond to requests from clients, receive data from the stations, forward the data to collaborating data centres, and provide the monitoring packets for further processing. Communication with every remote station's DAS is performed by using a specific port for data transfer (using RTP protocol) and a different port dedicated to commands and monitoring (using conventional TCP/IP). Thus, each DAS is operating in a multitasking mode as it is continuously sending data while receiving commands, while

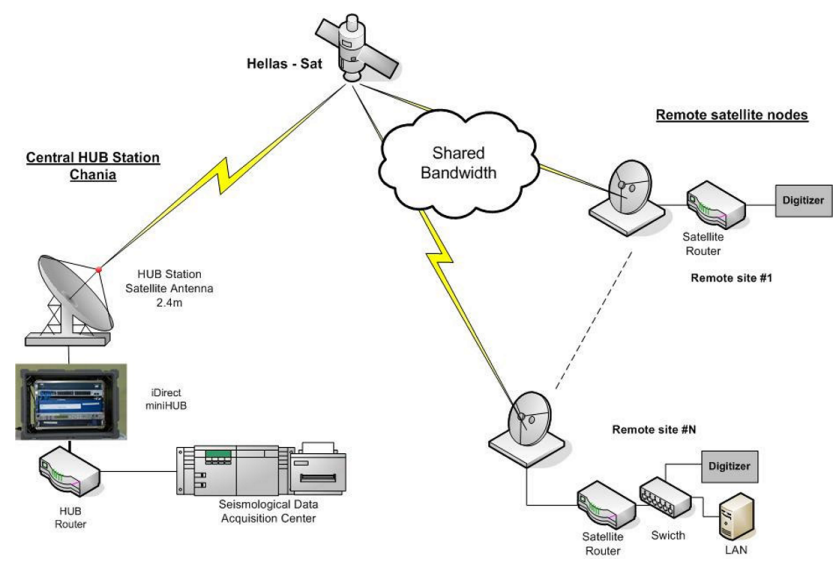

Fig. 4. VSAT satellite topology used by HSNC for remote stations with line-distance from NCDSA more than $200 \mathrm{~km}$, or for stations in small isolated isles in South Aegean.

at the same time sending its status. This scheme, except the obvious transmission speed benefits (since it has a channel dedicated to the data), provides a redundant path to access the remote DAS (in case of a RTP failure) by using the alternative port, thus ensuring reliability.

Control and monitoring is based on XML requests and responds. We developed a customised Java-based application for these purposes. By means of this custom-built solution the certified users are able to control and monitor the network using any available device (e.g. desktop, laptop, PDA, mobile 


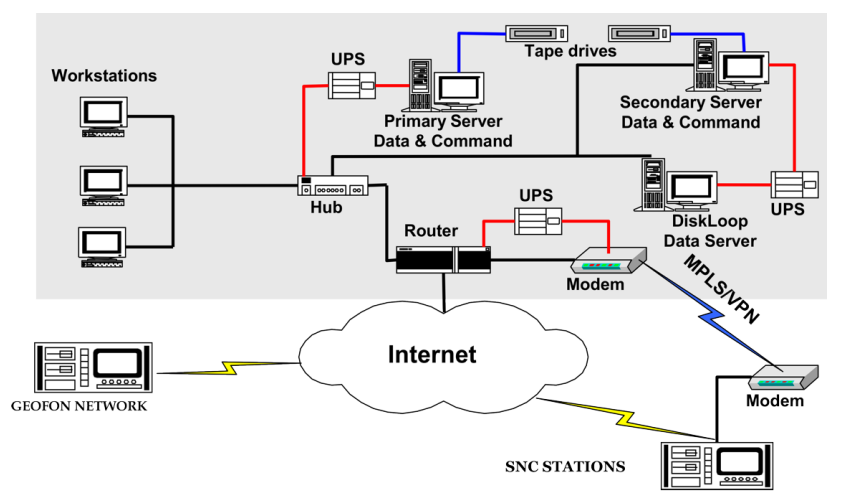

Fig. 5. Schematic topology of the Network Centre for Data Storage and Analysis Centre (NCDSA) of HSNC.

phones, smartphones) with IP based communications. Figure 6 presents the flow chart for controlling and monitoring HSNC's remote stations.

\section{Data processing}

The Seismic Network Data Processor (SNDP - Synapse Science Center, Russia) has been installed at the NCDSA of HSNC for interactive and automatic processing of the multichannel seismological recordings collected from the HSNC's remote stations. It consists of two main subsystems: (a) the Real-Time Subsystem (RTS) for multi-channel data collection, storage in Disk loop Data Server, and automated signal processing of the data flow; (b) an off-line Seismic Analysis Subsystem (SAS) for interactive processing of the registered seismograms that applies more sophisticated and time consuming procedures.

The main advantages of RTS are as follows:

- Asynchronous communication between different system processes (based on the port method).

- Semaphore facilities to control all of the shared computer resources.

- A unique System Process Table (SPT) in which all processes ports and their priorities are defined.

- A specific Global System Table (GST) which provides flexible system handling and easy modification of the system while including into it new tasks, methods, algorithms, and facilities.

Furthermore, the use of an internal $\mathrm{C}++-$ like scripting language allows the users to embed new data analysis algorithms and methods in the RTS and thus to optimize or evaluate them using on-line data streams. All the above intrinsic characteristics, along with the selection of a Unix-based operating system enable us to run several processes in parallel while feeding the results from each process to different stages. The processing stages involved are:

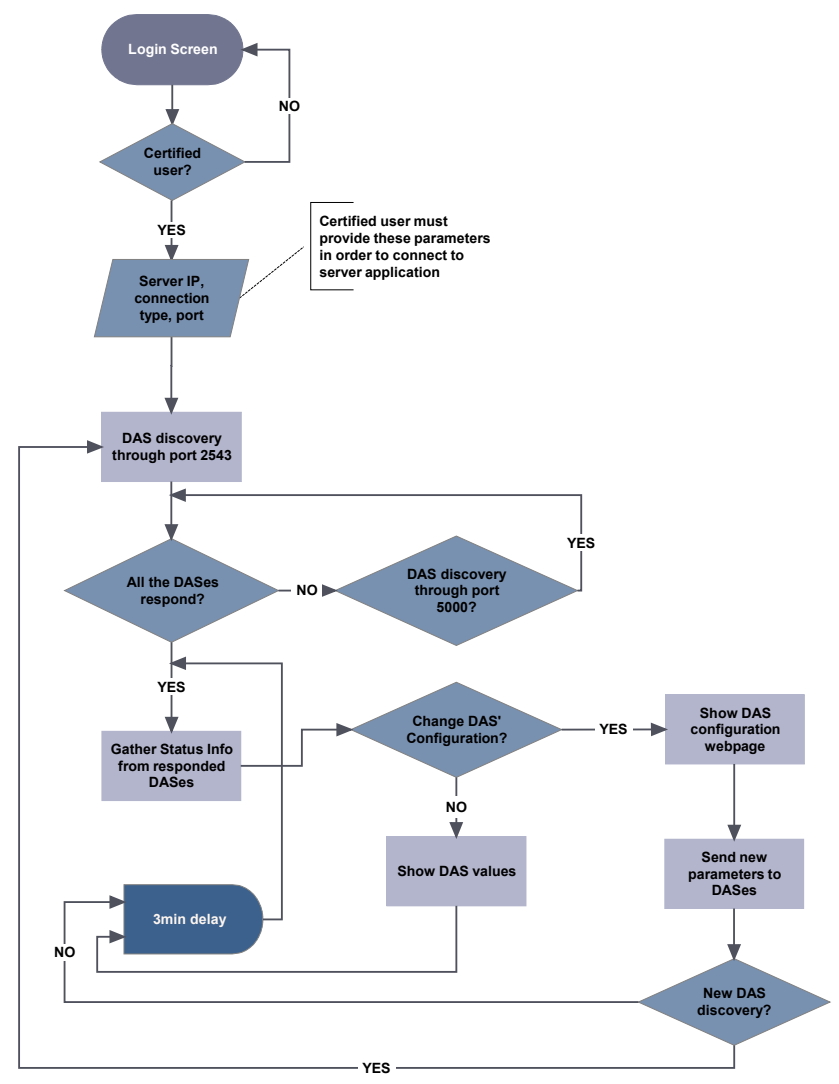

Fig. 6. Flow chart for controlling and monitoring HSNC's remote stations by certified users.

1. detection of seismic events;

2. identification and parameter estimation of seismic phases;

3. location of event sources;

4. identification of event types.

After successful completion of each stage, a selection criterion (e.g. entropy based, minimum $\mathrm{S} / \mathrm{N}$ ratio) is applied in order to select a unique solution. The last stage is the generation and issue of a final seismic bulletin where a variety of dissemination actions are performed: send seismic event alert by email to reporting centers and civil authorities, send list of phases to collaborating networks or organizations (e.g. HT, EMSC), update event database, prepare and send a snapshot of data to the analyst's workstation, produce maps and web results, send seismic event alert messages to registered users at alternative communication channels (MSN, GoogleTalk, Twitter, RSS feed), and send seismic alert SMS to the personnel on duty, if the earthquake magnitude is above a predefined threshold. A typical real example of a graphical seismic bulletin generated by HSNC for an event off coast of East Crete with $M_{\mathrm{W}} 5.7$ is given in Fig. 7. 

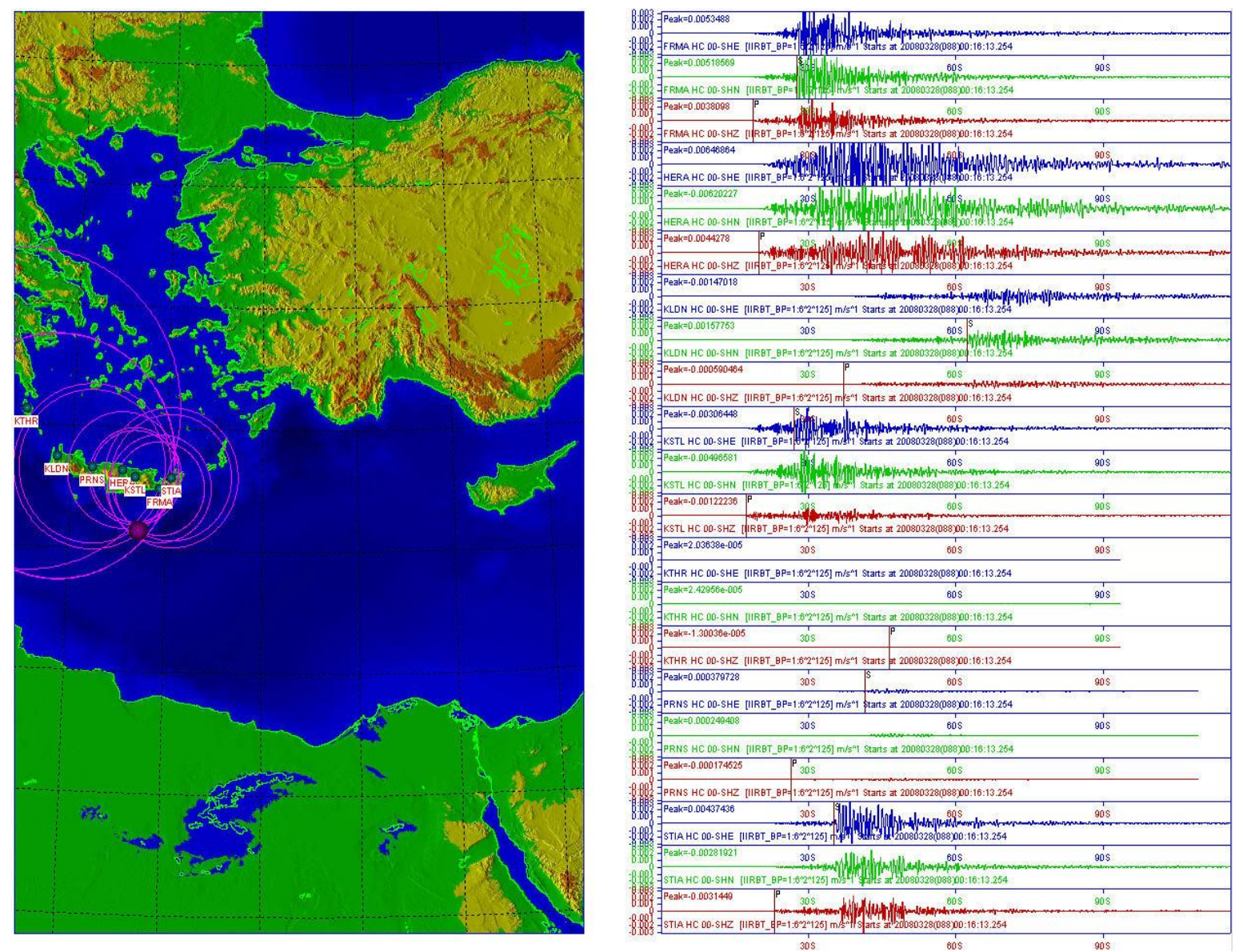

Fig. 7. A typical real example of a graphical seismic bulletin generated by HSNC for an event off coast of East Crete having $M_{\mathrm{W}} 5.7$, occurred on 28 March 2008 00:16:20 UTC with location $34.87^{\circ} \mathrm{N}, 25.52^{\circ} \mathrm{E}$ and depth $60 \mathrm{~km}$.

In addition to the conventional near real time seismological procedures (Fourier filtering, STA/LTA detection, events classification and association), the RTS of HSNC's SNDP is enhanced by additional scripts based on wavelet transformed seismic waveforms. Every waveform that is received in diskloop is transformed in 7 scales by using two different wavelet functions. The produced wavelet transformed waveforms are then fed, in parallel, to a de-noising sub-procedure. The result is a set of wavelet de-noised waveforms (with non-significant delay) along with the original recorded waveforms (Hloupis, 2009). The preceding methodology is applied to two real-time procedures: (a) a wavelet-based rapid estimation of earthquake magnitude oriented to early warning and (b) a rapid estimation of epicenter using recordings from two stations. In the first procedure, it has been shown that is possible to use the wavelet coefficients from specific scales in order to provide a quick estimation of the earthquake magnitude. The maximum amplitude of the wavelet coefficients at scales 6 and 7 seems to correlate adequately with the local reported magnitude. This allows the calculation of an empirical relation which associates the Wavelet
Coefficient Amplitude at the last scale with the local reported magnitude (Hloupis and Vallianatos, 2013). A typical example of a wavelet transformed waveform and correlation results from scale 7 is presented in Fig. 8a and b. A detailed analysis of the methodology along with an emerical formulation used to magnitude estimation in the frame of an earthquake early warning is given in Hloupis and Vallianatos (2013).

For the epicentral location, a recently proposed (Hloupis, 2009) novel technique has been implemented to HSNC's data processing, which combines two different known approaches from seismology (azimuth estimation and epicentral estimation using two stations). It has been shown that this technique can be efficiently used to estimate in real time the epicenter with improved accuracy and especially when it is located outside the area defined by the installed seismological network. The combination of latter two methods becomes very important when it comes to the development of a regional Earthquake Early Warning System. 

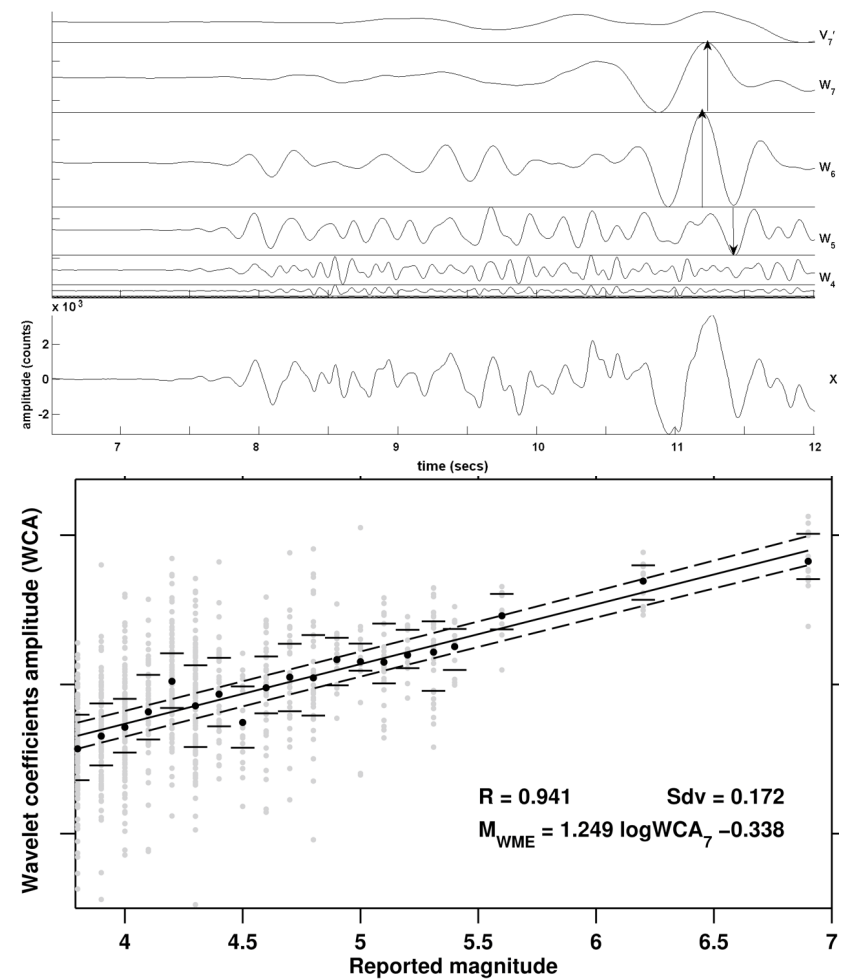

Fig. 8. (a) Wavelet transformed seismogram at 7 scales. The vertical arrow indicates the maximum amplitude coefficient at corresponding scale. (b) Correlation of wavelet amplitudes at scale 7 with earthquake magnitude. Results for individual seismograms are shown as gray dots the 25 th and 75 th percentile as thin black dashes, and the averages at every distinct magnitude as black squares. The thick line is the least squares best-fit line to the average values and the two dashed lines show the range of one standard deviation. The reported magnitudes were extracted from the EMSC catalog ( $M_{\text {L,EMSC }}$ (Hloupis and Vallianatos, 2013).

\section{Conclusions}

In the present work, the hardware and software technology used to operate HSNC is described. The main purposes of a seismological network such as HSNC are: detailed monitoring of seismicity, prompt and reliable earthquake information and alert, and significant contribution to the research of the earth's interior. However, the very first and most fundamental aim ever remains the accurate determination of earthquake location, resulting from the continuous and dense monitoring of the seismic area. The establishment and operation of a modern, dense seismological network in a region characterized by high seismicity, like the South Aegean, in the front of the Hellenic Arc, provides abundant data (waveforms, accurate earthquake catalogues, etc) that is extremely useful for the scientific community. HSNC provides a new and powerful seismic monitoring tool for studying tectonic processes in the most active seismic region of the South Aegean. Moreover, the numerous functions, from monitoring seismicity to characterizing seismogenic volumes, make HSNC an essential tool for assessing the seismic hazard of the region.

Acknowledgements. This work was implemented through the project entitled "Interdisciplinary Multi-Scale Research of Earthquake Physics and Seismotectonics at the Front of the Hellenic Arc (IMPACT-ARC)" in the framework of action "ARCHIMEDES III - Support of Research Teams at TEI of Crete" (MIS380353) of the Operational Program "Education and Lifelong Learning" and is cofinanced by the European Union (European Social Fund) and Greek national funds.

\section{References}

Becker, D.: Mikroseismizitiit und Deformation der Kruste Ostkreta, Diploma thesis, University of Hamburg, 2000 (in German).

D’Alessandro, A., Papanastassiou, D., and Baskoutas, I.: Hellenic Unified Seismological Network: an evaluation of its performance through SNES method, Geophys. J. Int., 185, 1417-1430, 2011.

Delibasis, N., Ziaza, M., Voulgaris, N., Papadopoulos, T., Stavrakakis, G., Papanastassiou, D., and Drakatos, G.: Microseismic activity and seismotectonics of Heraklion area (central Crete Island, Greece), Tectonophysics, 8, 237-248, 1999.

Dewey, J. F., Helman, J. L., Turco, E., Hutton, D. W. H., and Knott, S. D.: Kinematics of the Western Mediterrannean, in: Alpine Tectonics, Geological Society, edited by: Coward, M. P. and Dietrich, D., London, Special Publications, 45, 265-283, 1989.

Comninakis, P. E. and Papazachos, B. C.: Seismicity of the Eastern Mediterranean and some tectonic features of the Mediterranean ridge, Bull. Geol. Soc. Am., 83, 1093-1102, 1972.

Harjes, H.-P., Janik, M., Biisselberg, T., Knapmeyer, M., Schmidt, H., Schweitzer, J., and Vafides, A.: Structure and dynamics of the Hellenic subduction zone under Crete from seismic array measurements, Abstract IASPEI 97, 18, Thessaloniki, 1997.

Hloupis, G.: Seismological Data Acquisition and Signal Processing using Wavelets, PhD Thesis, Brunel University, UK, 2009.

Hloupis, G. and Vallianatos, F.: Wavelet-Based Rapid Estimation of Earthquake Magnitude Oriented to Early Warning, IEEE Geosci. Remote Sens. Lett., 10, 43-47, 2013.

Jackson, J.: Active tectonics of the Aegean region, Ann. Rev. Earth Planet. Sci., 22, 239-271, 1994.

Jost, M. L., Knabenbauer, O., Cheng, J., and Harjes, H.: Fault plane solutions of microearthquakes and small events in the Hellenic arc, Tectonophysics, 356, 87-14, 2002.

Karagianni, E. E., Papazachos, C. B., Panagiotopoulos, D. G., Suhadolc, P., Yuan, A., and Panza, G. F.: Shear velocity structure in the Aegean area obtained by inversion of Rayleigh waves, Geophys. J. Int., 160, 127-143, 2005.

Lallemant, S., Truffert, C., Jolivet, L., Henry, P., Chamot-Rooke, N., and de Voogd, B.: Spatial transition from compression to extension in the western Mediterranean ridge, Tectonophysics, 234, 33-52, 1994.

Le Pichon, X., Chamot-Rooke, N., Lallemant, S., Noomen, R., and Veis, G.: Geodetic determination of the kinematics of central Greece with respect to Europe: implications for eastern Mediterranean tectonics, J. Geophys. Res., 100, 12675-12690, 1995.

Makropoulos, K. C. and Burton, P. W.: Greek tectonics and seismicity, Tectonophysics, 106, 275-304, 1984. 
McClusky, S., Balassanian, S., Barka, A., Demir, C., Ergintav, S., Georgiev, I., Gurkan, O., Hamburger, M., Hurst, K., Kahle, H., Kastens, K., Kekelidze, G., King, R., Kotzev, V., Lenk, O., Mahmoud, S., Mishin, A., Nadariya, M., Ouzounis, A., Paradissis, D., Peter, Y., Prilepin, M., Reilinger, R., Sanli, I., Seeger, H., Tealeb, A., Toksöz, M. N., and Veis, G.: Global Position System constraints on plate kinematics and dynamics in the eastern Mediterranean and Caucasus, J. Geophys. Res., 105, 5695-5719, doi:10.1029/1996JB900351, 2000.
Meier, T., Rische, M., Endrun, B., Vafidis, A., and Harjes, H.: Seismicity of the Hellenic subduction zone in the area of western and central Crete observed by temporary local seismic networks, Tectonophysics, 383, 149-169, 2003.

Papazachos, B. C.: Seismicity of the Aegean and surrounding area, Tectonophysics, 178, 287-308, 1990. 